\title{
OTIMIZAÇÃO DOS PARÂMETROS DE HIDRÓLISE ENZIMÁTICA DO BAGAÇO DE CANA-DE-AÇÚCAR
}

\author{
Fabiano Bisinella Scheufele \\ Alan de Siqueira Butzke ${ }^{1}$ \\ Isabela Furquim Marra ${ }^{1}$ \\ Salah Din Mahmud Hasan ${ }^{1}$ \\ Mônica Lady Fiorese ${ }^{1}$
}

\begin{abstract}
Resumo: Devido ao contexto atual da diminuição dos combustíveis fósseis alavancando a necessidade de fontes energéticas de origem renovável, tem-se focado muito na conversão de biomassas lignocelulósicas via hidrólise enzimática. Neste trabalho objetivou-se avaliar e otimizar as condiçôes da hidrólise enzimática do bagaço de cana-de-açúcar a partir de celulases produzidas por fermentação em estado sólido (FES) com o fungo Trichoderma sp oriundo do bioma amazônico. Inicialmente realizou-se o pré-tratamento alcalino oxidativo no bagaço de cana-de-açúcar, utilizando-o como substrato na FES para a produção de celulases com Trichoderma sp. O extrato enzimático celulolítico produzido alcançou atividade de $0,162 \mathrm{U} \cdot \mathrm{mL}^{-1} \mathrm{e}$ foi utilizado na hidrólise enzimática do bagaço de cana visando a produção de açúcares fermentescíveis. Através da metodologia de superfícies de resposta avaliou-se as variáveis tempo de hidrólise ( $\mathrm{t}$ ), diluição da enzima (D), concentração de Tween 80 (C) e razão sólido:líquido (R) sobre a resposta da atividade enzimática da celulase. Foi utilizada também uma enzima comercial nos testes de hidrólise para fins de comparação. Os maiores níveis de atividade enzimática obtidos foram 0,324 e $0,362 \mathrm{U} \cdot \mathrm{mL}^{-1}$ para a enzima produzida e a comercial, respectivamente, no tempo de $90 \mathrm{~min}$, diluição de enzima de 1,0, na razão sólido:líquido de 30 g.L $\mathrm{L}^{-1}$ e concentração de Tween de $1 \%$.
\end{abstract}

Palavras chave: Celulases, fermentação em estado sólido, hidrólise enzimática, resíduos lignocelulósicos.

Abstract: Recently, the search of renewable sources of energy has grown due to the depleting of fossil fuels, increasing the possibility at the conversion of the lignocellulosic biomass via hydrolytic enzymes. The aim of this paper was to evaluate and optimize the enzymatic hydrolysis conditions of the sugarcane bagasse by cellulases produced by solid-state fermentation (SSF) with the Trichoderma sp. fungi from the amazon biome. The substrate for the cellulases production at the SSF was the sugarcane bagasse previously pretreated. The cellulolytic extract reached an enzymatic activity of $0.162 \mathrm{U} \cdot \mathrm{mL}^{-1}$ and was employed at the enzymatic hydrolysis aiming the production of fermentable sugars. Using the response surface methodology the parameters hydrolysis time $(\mathrm{t})$, enzyme dilution (D), Tween 80 concentration $(\mathrm{C})$ and solid-liquid ratio (R) were evaluated at the enzymatic activity response. Another commercial enzyme was used at the essays to establish a comparison. The higher yield of enzymatic activity was 0.324 and $0.362 \mathrm{U} . \mathrm{mL}^{-1}$ for the produced and the commercial enzyme, respectively at the hydrolysis time of $90 \mathrm{~min}$, enzyme dilution of 1.0, solid-liquid ratio of 30 g. $\mathrm{L}^{-1}$ and Tween 80 concentration of $1 \%$.

Keywords: Cellulases, solid-state fermentation, enzymatic hydrolysis, lignocellulosic waste.

1 Programa de Pós-Graduação em Engenharia Química da Universidade Estadual do Oeste do Paraná. 


\section{INTRODUÇÃO}

A possibilidade de produzir combustíveis derivados da maior fonte de carbono existente no planeta, a lignocelulose, tem incentivado grandes investimentos na indústria de biocombustíveis (Bansal et al., 2009). O bioetanol proveniente de biomassas lignocelulósicas apresenta-se como uma tecnologia promissora, pois sua matéria-prima é extremamente abundante, possui alta disponibilidade e baixo custo (Kang et al., 2004; Fitzpatrick et al., 2010). Pode ainda contribuir majoritariamente na redução dos gases do efeito estufa. Uma mistura de $10 \%$ de bioetanol na gasolina reduz a emissão de dióxido de carbono de 3 a $6 \%$, tornando o bioetanol um combustível mais limpo além de ser uma alternativa renovável ao petróleo (Singhania et al., 2010).

As biomassas vegetais contêm grandes quantidades de celulose, além de outros polissacarídeos hidrolisáveis em glicose para fermentação a etanol combustível ou para a produção de produtos químicos de interesse. Na natureza a biodegradação é lenta, pois a lignina e a cristalinidade dos substratos restringem o acesso das enzimas hidrolíticas aos componentes dos polissacarídeos. Entretanto, a biomassa pode ser pré-tratada e fracionada, utilizando processos que envolvem altas temperaturas e pressão, combinadas a catálises ácidas ou básicas, liberando os materiais lignocelulósicos em condiçôes mais acessíveis ao ataque das enzimas (Palonen et al., 2004). A utilização de resíduos da agroindústria brasileira, além de fornecer diferentes alternativas de substratos para a fermentação, também ajudam nos problemas de poluição (Pandey et al., 2000a).

O grande potencial de mercado e o papel importante que as celulases agregam sobre as indústrias de bioenergia e produtos de origem biológica causam uma grande motivação no desenvolvimento de enzimas celulolíticas aprimoradas que se aplicam à hidrólise da celulose das paredes celulares vegetais. Estas celulases devem possuir algumas características necessárias para sua aplicação em biorrefinarias como alta eficiência catalítica em substratos celulósicos insolúveis, estabilidade em temperaturas elevadas e a determinados $\mathrm{pH}$ e alta tolerância a inibição por produto (Zhang et al., 2006).

As celulases são enzimas fundamentais na bioconversão de substratos celulósicos em produtos de valor agregado. Atualmente, a produção das celulases é a etapa que confere maior custo, aproximadamente $40 \%$, do valor total de produção de etanol proveniente de biomassa lignocelulósica (Chandra et al., 2010).

O processo de hidrólise enzimática envolve a ação sinérgica entre enzimas celulolíticas que apresentam um alto custo associado a uma baixa produção (Zhang et al., 2006). Diversas pesquisas têm sido realizados na busca de enzimas capazes de hidrolisar a celulose de maneira mais efetiva, seja pela otimização de processos fermentativos, pela combinação de enzimas para a obtenção de complexos celulásicos mais eficientes ou pelo melhoramento de espécies por meio de métodos de engenharia genética (Imai et al., 2004; Kang et al., 2004).

A grande maioria das celulases comerciais são produzidas pelo fungos filamentosos Trichoderma reesei ou Aspergillus niger por fermentação submersa (FSm). Fungos possuem maior interesse comercial devido à capacidade de níveis de secreção protéica maiores que 100 g. $\mathrm{L}^{-1}$, e à possibilidade de suas enzimas atuarem naturalmente de maneira bastante efetiva na hidrólise da biomassa (Chundawat et al., 2011).

O desempenho da produção destas enzimas é intensamente influenciada por diversos parâmetros incluindo a natureza do substrato celulósico, o pH do meio, disponibilidade de nutrientes, suplementação com indutores, temperatura de fermentação, entre outros. A produção industrial, em larga escala, das celulases requerem o entendimento e controle dos parâmetros envolvidos no crescimento do micro-organismo e de sua capacidade produtiva da enzima (Singhania et al., 2010). O custo e os baixos teores de produção destas enzimas são os principais fatores a serem superados para a aplicaçáo industrial do processo. Reduzir os custos de produçáo por meio da otimizaçáo do meio fermentativo e o processo é o objetivo da pesquisa básica para aplicaçóes industriais (Park et al., 2002; Kang et al., 2004; Latifian et al., 2007).

Atualmente, a grande maioria das enzimas utilizadas industrialmente são produzidas fazendo uso da FSm, geralmente utilizando-se micro-organismos geneticamente modificados. No entanto, o custo da produção destas enzimas por FSm é alto e o processo torna-se, muitas vezes, economicamente inviável (Pandey et al., 2000a). Desta forma, a fermentação em estado sólido pode ser 
considerada uma alternativa atraente na redução dos custos de produçáo destas enzimas (Pandey et al., 2000b).

O objetivo deste trabalho foi avaliar e otimizar as condiçôes da hidrólise enzimática do bagaço de cana-de-açúcar a partir de um complexo celulolítico produzido pela FES do bagaço de cana pelo micro-organismo de origem amazônica do gênero Trichoderma sp., este trabalho foi baseado em uma dissertaçáo de mestrado (Scheufele, 2012).

\section{MATERIAIS E MÉTODOS}

\section{MICRO-ORGANISMO E FES}

O micro-organismo utilizado neste trabalho foi o fungo Trichoderma sp. 1382, cedido pelo Instituto Nacional de Pesquisas da Amazônia INPA, conservado sob refrigeração a $4^{\circ} \mathrm{C}$ em meio inclinado PDA (Potato Dextrose Agar), sendo repicado periodicamente. O preparo do inóculo em meio PDA inclinado em temperatura constante de $30^{\circ} \mathrm{C}$ por um período de 7 dias. A contagem dos esporos foi realizada em câmara de Neubauer (Scheufele, 2012).

O resíduo lignocelulósico utilizado no estudo da hidrólise enzimática foi o bagaço da cana-de-açúcar, o qual foi submetido a um pré-tratamento conforme metodologia proposta por Krishna (2000), o qual usou tratamento alcalino oxidativo com peróxido de hidrogênio $1 \%(\mathrm{v} / \mathrm{v})$ no $\mathrm{pH} 11,5$, após retirada do conteúdo solúvel do resíduo lignocelulósico por meio de lavagem com água destilada (Scheufele, 2012).

A produção das enzimas celulases foi realizada através de FES em batelada em frascos erlenmeyer à $30^{\circ} \mathrm{C}$, temperatura em que o fungo apresenta maior crescimento, em estufa bacteriológica. A solução nutriente utilizada foi a de Mandels \& Weber (1969), preparada em tampão fosfato $50 \mathrm{mM} \mathrm{pH} \mathrm{7,0.} \mathrm{Após} \mathrm{autoclavagem} \mathrm{do} \mathrm{substrato}$ (bagaço de cana pré-tratado) adicionou-se a soluçáo nutriente e ajustou-se a umidade na proporção sólido-líquido de 1:9. A concentração inicial de esporos utilizada foi de $1 \times 10^{7}$ esporos. ${ }^{-1}$. A fermentação decorreu por um período de $144 \mathrm{~h}$, baseada em resultados de fermentaçóes realizadas anteriormente (Scheufele, 2012). Após a fermentação, o complexo enzimático da celulase foi obtido por extração com tampão fosfato de sódio 50
$\mathrm{mM}$ pH 7,0, na proporção 1:17 em incubadora shaker por $2 \mathrm{~h}$, a $35^{\circ} \mathrm{C}$ e agitaçáo de $150 \mathrm{rpm}$.

Além da celulase produzida por fermentação em estado sólido, utilizou-se também um extrato enzimático preparado com enzima celulase comercial SIGMA (EC 232-734-4) produzida por Aspergillus niger, este foi diluído para obtenção de mesma atividade enzimática do extrato enzimático obtido pelo fungo Trichoderma sp.

\section{HIDRÓLISE ENZIMÁTICA}

Os testes de hidrólise enzimática para a celulase produzida por FES e para a celulase comercial foram realizados em tubos de ensaio, nos quais foram adicionados o substrato (bagaço de cana-de-açúcar pré-tratado com $\mathrm{H}_{2} \mathrm{O}_{2}$ ) na quantidade adequada a cada experimento, $4 \mathrm{~mL}$ de tampáo citrato $50 \mathrm{mM} \mathrm{pH}$ 4,8 e $2 \mathrm{~mL}$ da solução enzimática devidamente diluída. A temperatura foi mantida constante em $50^{\circ} \mathrm{C}$ em banho aquecido termostático, a agitação foi realizada a cada $10 \mathrm{~min}$, terminada a incubação os ensaios foram submetidos a determinação dos açúcares redutores. Os testes de hidrólise foram feitos para ambos os extratos enzimáticos seguindo planejamentos fatoriais.

\section{MÉTODOS ANALÍTICOS}

A determinação da concentração de açúcares redutores realizou-se conforme a metodologia proposta por Miller (1959), a partir do reagente DNS (ácido 3,5-dinitrosalicílico), com uma sensibilidade na faixa de 0,1 a 1,0 g.L $L^{-1}$ de açúcar redutor expresso como glicose. A atividade enzimática total (FPase) do complexo celulásico foi determinada a partir da adaptação do método de atividade enzimática em papel filtro preconizado por Ghose (1987). A atividade enzimática foi expressa em unidade internacional de atividade enzimática $\left(\mathrm{U} \cdot \mathrm{mL}^{-1}\right)$, a qual corresponde a quantidade de enzima que libera $1 \mu \mathrm{mol}$ de açúcar redutor por $\mathrm{mL}$ de caldo por min, sob as condiçóes do ensaio. A absorbância foi medida em espectrofotômetro UV-Vis (Shimadzu UV-1800) em comprimento de onda de $540 \mathrm{~nm}$.

\section{PLANEJAMENTO EXPERIMENTAL}

Visando analisar influência dos parâmetros sobre a hidrólise enzimática, foi feito primeira- 
mente um planejamento experimental fatorial fracionário do tipo $2^{4-1}$, no qual foram testadas as variáveis: tempo de hidrólise $(\mathrm{t})$, diluição da enzima (D), concentração de Tween 80 (C) e razão sólido:líquido $(\mathrm{R})$ variando conforme os níveis apresentados na Tabela 1.

Tabela 1. Especificação dos níveis das variáveis avaliadas no planejamento fatorial fracionário $2^{4-1}$ da hidrólise do bagaço de cana-de-açúcar.

\begin{tabular}{|l|c|c|c|}
\hline \multirow{2}{*}{ Variáveis } & \multicolumn{3}{|c|}{ Níveis } \\
\cline { 2 - 4 } & $(-1)$ & 0 & $(+1)$ \\
\hline Tempo de hidrólise - t (min) & 30 & 60 & 90 \\
\hline Diluição da enzima - D (v/v) & 0,33 & 0,66 & 1,0 \\
\hline $\begin{array}{l}\text { Concentração de Tween } 80- \\
\text { C (\%) }\end{array}$ & 0 & 0,5 & 1,0 \\
\hline Razão sólido-líquido - R (g.L-1 $)$ & 10 & 20 & 30 \\
\hline
\end{tabular}

As variáveis significativas sobre a hidrólise foram submetidas a otimização do processo de hidrólise, por meio da utilizaçáo de delineamento composto central rotacional (DCCR), o qual utiliza a metodologia de superfícies de resposta. Os valores experimentais obtidos foram ajustados ao modelo de segunda ordem conforme a Equaçáo (1):

$$
\begin{aligned}
& Y=B_{0}+B_{1} X_{1}+B_{2} X_{2}+B_{11} X_{1}^{2} \\
& +B_{22} X_{2}{ }^{2}+B_{12} X_{1} X_{2}
\end{aligned}
$$

Onde $\mathrm{Y}$ é a resposta predita de atividade enzimática das celulases (U.mL $\left.{ }^{-1}\right), \mathrm{X}_{1}$ e $\mathrm{X}_{2}$ os parâmetros analisados (D) e (R), $B_{0}$ é o valor constante do intercepto, $\mathrm{B}_{1}$ e $\mathrm{B}_{2}$ os coeficientes lineares de $\mathrm{X}_{1}$ e $\mathrm{X}_{2}$, respectivamente, $\mathrm{B}_{11}$ e $\mathrm{B}_{22}$ os coeficientes quadráticos de $\mathrm{X}_{1}$ e $\mathrm{X}_{2}$ e $\mathrm{B}_{12}$ o coeficiente da interação entre as variáveis $\mathrm{X}_{1} \mathrm{e} \mathrm{X}_{2}$.

A análise de variância (ANOVA) foi utilizada na análise da regressão aos dados experimentais e das superfícies de resposta. A qualidade do ajuste do modelo quadrático foi expresso pelo coeficiente de determinação $\left(\mathrm{R}^{2}\right)$.

No planejamento DCCR, fixou-se os parâmetros apontados como não significativos pelo planejamento fracionário $2^{4-1}$ : concentração de Tween 80 no nível inferior, ou seja, zero (sem Tween 80) e o tempo de hidrólise foi mantido em $60 \mathrm{~min}$, sabendo-se que a metodologia de determinação de atividade enzimática da celulase utiliza este tempo como padrão. As variáveis estudadas no delineamento composto central rotacional foram desta forma, a diluição da enzima (D) e a razão sólido-líquido do bagaço $(\mathrm{R})$, nas quais os níveis utilizados são apresentados na Tabela 2 .

Tabela 2. Especificação dos níveis das variáveis avaliadas no planejamento DCCR da hidrólise do bagaço de cana-de-açúcar.

\begin{tabular}{|l|c|c|c|c|c|}
\hline \multirow{2}{*}{ Variáveis } & \multicolumn{5}{|c|}{ Níveis } \\
\cline { 2 - 6 } & $(-1,414)$ & $(-1)$ & 0 & $(+1)$ & $(+1,414)$ \\
\hline $\begin{array}{l}\text { Diluição } \\
\text { da enzima } \\
- \text { D (v/v) }\end{array}$ & 0,5 & 0,57 & 0,75 & 0,93 & 1 \\
\hline $\begin{array}{l}\text { Razáo } \\
\text { sólido- } \\
\text { líquido - } \\
\text { R (g.L-1) }\end{array}$ & 20 & 22,9 & 30 & 37,1 & 40 \\
\hline
\end{tabular}

Os resultados obtidos na hidrólise enzimática foram analisados no software STATISTICA ${ }^{\mathrm{TM}}$ (v. 8.0) onde foi realizada uma estimativa dos efeitos das variáveis e suas interaçóes sobre a resposta analisada, considerando o nível de significância de 5\%. Gerou-se também a análise de variância (ANOVA) que tem como objetivo testar a validade do modelo matemático obtido, através do teste $\mathrm{F}$ e do cálculo do coeficiente de determinação do modelo $\left(\mathrm{R}^{2}\right)$. A metodologia de superfície de resposta foi usada para otimizar as condiçóes de hidrólise e fornecer um modelo matemático adequado para as respostas de AE. Modelos obtidos com baixos valores de $\mathrm{R}^{2}$ são desconsiderados para fins de otimização, servindo apenas para atestar a influência das variáveis sobre a resposta (Barros Neto et al., 2010).

\section{RESULTADOS E DISCUSSÃO}

No estudo da hidrólise enzimática do bagaço de cana pré-tratado com peróxido de hidrogênio (1\%) utilizou-se a metodologia de superfície de resposta como ferramenta na otimização do processo. Dois tipos de planejamento foram realizados, primeiramente um planejamento fatorial fracionário $2^{4-1}$ foi utilizado para a triagem de variáveis. Em seguida um planejamento composto central rotacional (DCCR) foi aplicado 
para a obtenção de um modelo quadrático do processo.

Ambos os planejamentos foram utilizados tanto para a enzima produzida por fermentaçáo em estado sólido (FES) quanto para a enzima comercial, de forma a estabelecer uma comparação entre as enzimas. A celulase produzida por FES pelo micro-organismo Trichoderma sp. alcançou uma AE de 0,162 U.mL ${ }^{-1}$ ou 2,778 U.g ${ }^{-1}$, nas condiçóes de uma proporção sólido-líquido de 1:9 e $\mathrm{pH} 7,0$. Desta maneira a enzima comercial utilizada foi diluída para obtenção da mesma atividade enzimática.

Latifian et al., (2007) por meio de metodologias de superfícies de resposta estudaram a produção de celulase por FES com farelo de arroz com dois micro-organismos do gênero Trichoderma sp., avaliando os parâmetros temperatura $\left(25,30\right.$ e $\left.35^{\circ} \mathrm{C}\right)$, umidade $(40,55$ e $70 \%)$ e $\mathrm{pH}(4,5$ e 6$)$. Verificaram que para o micro-organismo T. reesei QM9414 a máxima atividade enzimática da celulase obtida foi de 1,1635 U.g $\mathrm{g}^{-1}$ observada no $\mathrm{pH} 5,0$, umidade de $70 \%$ e temperatura de $30^{\circ} \mathrm{C}$. Para o micro-organismo T. reesei MCG77, a AE máxima encontrada foi de 2,314 U.g $\mathrm{g}^{-1}$ no $\mathrm{pH} 5,0$, umidade de $70 \%$ e temperatura de $30^{\circ} \mathrm{C}$.

O micro-organismo amazônico Trichoderma sp. apresentou uma produção considerável de celulases pela FES do bagaço de cana pré-tratado alcançando teores enzimáticos comparáveis aos obtidos por cepas geneticamente modificadas como os utilizados por Latifian et al., (2007).

\section{AVALIAÇÃO DOS PARÂME-TROS SOBRE A HIDRÓLISE ENZIMÁTICA}

Dentre as variáveis estudadas no planejamento fracionário $2^{4-1} \mathrm{o}$ tempo de hidrólise foi baseado na determinação de AE em papel filtro, conforme Ghose (1987), a qual utiliza o tempo de $60 \mathrm{~min}$, de forma que utilizou-se este como nível central no planejamento. A diluição da enzima foi avaliada com o intuito de estudar a possibilidade de economizar o extrato enzimático, fator que afeta consideravelmente o custo do processo. Avaliou-se também a influência da adição do surfactante Tween 80 na hidrólise, visto que a literatura cita a melhoria de processos de hidrólise com sua utilização. A razão sólido-líquido foi variada para obter a quantidade de sólido utilizada por ensaio na hidrólise, neste caso o fator limitante é a sua concentração máxima, a qual apresenta consistência muito elevada para valores maiores que os utilizados.

A adição de surfactantes durante a hidrólise pode modificar propriedades na superfície da celulose e minimizar a adsorção irreversível das celulases sobre a celulose. Os surfactantes não iônicos, classe na qual se enquadra o Tween 80 , são tidos como os mais adequados na melhoria da hidrólise da celulose (Sun \& Cheng, 2002)

Segundo Eriksson et al., (2002) uma alta conversão de celulose em açúcares fermentescíveis requer uma alta carga enzimática, deixando o processo pouco viável economicamente. A adição de surfactantes potencializa a hidrólise enzimática, entretanto os mecanismos do aumento da conversão enzimática pela adição de surfactantes é desconhecido. Avaliando diferentes tipos de surfactantes no mecanismo de hidrólise enzimática da lignocelulose, os autores averiguaram que os surfactantes não iônicos foram os mais efetivos, incluindo o Tween 20 e 80.

$\mathrm{Na}$ Tabela 3, observa-se a matriz do planejamento, com as variáveis nas suas formas codificadas e reais, e os resultados obtidos de atividade enzimática da celulase para a enzima proveniente da fermentação em estado sólido $\left(\mathrm{AE}_{\mathrm{FES}}\right)$ e para a enzima comercial $\left(\mathrm{AE}_{\mathrm{EC}}\right)$ obtidos na hidrólise do bagaço de cana pré-tratado.

A partir dos resultados apresentados na Tabela 3, verifica-se que o ensaio 8 , nível superior (+1) para todas as variáveis, resultou nos melhores resultados para ambas enzimas. Neste ensaio obtiveram-se valores de atividade enzimática 0,324 U.mL $L^{-1}$ e 0,362 U. $\mathrm{mL}^{-1}$ para as enzimas por FES e comercial, respectivamente. Observando-se os ensaios 9 a 12, a quadruplicata no ponto central, nota-se que as atividades enzimáticas não variam de maneira expressiva, indicando uma boa repetibilidade entre os resultados dos ensaios.

A estimativa dos efeitos principais para o planejamento fracionário são apresentadas na Tabela 4 , juntamente com os valores obtidos para o erro padrão, p-valor, valores dos coeficientes das variáveis no modelo. Os valores destacados em negrito e itálico indicam que o efeito é significativo para o intervalo de confiança de $95 \%$ (p-valor < $0,05)$. 
Tabela 3. Matriz do planejamento $2^{4-1}$ com quadruplicata no ponto central com os valores codificados e reais.

\begin{tabular}{|c|c|c|c|c|c|c|}
\hline \multirow{2}{*}{ Ensaio } & \multicolumn{5}{|c|}{ Variáveis } & \multicolumn{2}{c|}{ Respostas $^{-4}$} \\
\cline { 2 - 7 } & $\mathrm{t}$ & $\mathrm{D}$ & $\mathrm{C}$ & $\mathrm{R}$ & $\mathrm{AE}_{\mathrm{FES}}\left(\mathrm{U}_{\mathrm{mL}}{ }^{-1}\right)$ & $\mathrm{AE}_{\mathrm{EC}}\left(\mathrm{U} \cdot \mathrm{mL}^{-1}\right)$ \\
\hline 1 & $-1(30)$ & $-1(0,33)$ & $-1(0)$ & $-1(10)$ & 0,063 & 0,074 \\
\hline 2 & $+1(90)$ & $-1(0,33)$ & $-1(0)$ & $+1(30)$ & 0,095 & 0,127 \\
\hline 3 & $-1(30)$ & $+1(1,0)$ & $-1(0)$ & $+1(30)$ & 0,179 & 0,321 \\
\hline 4 & $+1(90)$ & $+1(1,0)$ & $-1(0)$ & $-1(10)$ & 0,179 & 0,238 \\
\hline 5 & $-1(30)$ & $-1(0,33)$ & $+1(1 \%)$ & $+1(30)$ & 0,103 & 0,122 \\
\hline 6 & $+1(90)$ & $-1(0,33)$ & $+1(1 \%)$ & $-1(10)$ & 0,087 & 0,076 \\
\hline 7 & $-1(30)$ & $+1(1,0)$ & $+1(1 \%)$ & $-1(10)$ & 0,173 & 0,216 \\
\hline 8 & $+1(90)$ & $+1(1,0)$ & $+1(1 \%)$ & $+1(30)$ & 0,324 & 0,362 \\
\hline 9 & $0(60)$ & $0(0,66)$ & $0(0,5 \%)$ & $0(20)$ & 0,165 & 0,192 \\
\hline 10 & $0(60)$ & $0(0,66)$ & $0(0,5 \%)$ & $0(20)$ & 0,168 & 0,187 \\
\hline 11 & $0(60)$ & $0(0,66)$ & $0(0,5 \%)$ & $0(20)$ & 0,173 & 0,179 \\
\hline 12 & $0(60)$ & $0(0,66)$ & $0(0,5 \%)$ & $0(20)$ & 0,162 & 0,187 \\
\hline
\end{tabular}

Tabela 4. Estimativa dos efeitos do planejamento fracionário $2^{4-1}$ para a hidrólise enzimática do bagaço para as enzimas FES e EC.

\begin{tabular}{|c|c|c|c|c|c|c|}
\hline \multirow{2}{*}{ Intercepto } & \multicolumn{3}{|c|}{ Enzima FES $\left(\mathrm{AE}_{\mathrm{FES}}\right)$} & \multicolumn{3}{c|}{ Enzima Comercial $\left(\mathrm{AE}_{\mathrm{EC}}\right)$} \\
\cline { 2 - 6 } & p-valor & Coeficiente & Erro & p-valor & Coeficiente & Erro \\
\cline { 2 - 6 } & 0,000 & 0,156 & 0,008 & 0,000 & 0,190 & 0,006 \\
\hline $\mathrm{t}$ & 0,082 & 0,021 & 0,010 & 0,245 & 0,009 & 0,007 \\
\hline $\mathrm{D}$ & 0,000 & 0,063 & 0,010 & 0,000 & 0,092 & 0,007 \\
\hline $\mathrm{C}$ & 0,075 & 0,022 & 0,010 & 0,778 & 0,002 & 0,007 \\
\hline $\mathrm{R}$ & 0,046 & 0,025 & 0,010 & 0,001 & 0,041 & 0,007 \\
\hline & $\mathrm{R}^{2}=0,881$ & & & $\mathrm{R}^{2}=0,968$ & & \\
\hline
\end{tabular}

$\mathrm{Na}$ Tabela 4 é possível verificar que os planejamentos para ambas as enzimas obtiveram comportamento similar no que se refere as variáveis significativas sobre o processo de hidrólise do bagaço. As variáveis, diluição da enzima (D) e razão sólido-líquido $(\mathrm{R})$ são as variáveis significativas para ambas as enzimas, ao passo que as variáveis tempo de hidrólise e concentração de Tween 80 não exerceram influência significativa sobre o processo. Através dos valores dos coeficientes verifica-se que as variáveis $\mathrm{D}$ e $\mathrm{R}$ influenciam positivamente sobre a resposta (AE), ou seja, aumentando o valor destes parâmetros maiores teores enzimáticos serão obtidos.

Nota-se que o valor do coeficiente de correlação $\left(\mathrm{R}^{2}\right)$ do planejamento com a enzima comercial foi mais elevado que o da enzima produzida por FES, isto pode ter ocorrido devido ao fato da utilização do extrato enzimático bruto ser sem purificação, tornando-o menos homogêneo que a enzima comercial.

Planejamentos fracionários são utilizados apenas para a triagem de variáveis não sendo aplicados para a obtenção de modelos, entretanto é possível estabelecer superfícies de resposta para indicar a direção a ser tomada nos próximos experimentos, na Figura 1 são apresentadas as superfícies de resposta do planejamento fracionário $2^{4-1}$ para a $\mathrm{AE}$ em função das variáveis significativas D e R.

As superfícies de resposta (Figura 1) indicam que aumentando-se a razão sólido-líquido e para extratos enzimáticos mais concentrados, ou seja, maiores valores de $\mathrm{D}$ maiores atividades enzimáticas serão obtidas.

Dentre as variáveis avaliadas no planejamento é possível afirmar que a razão sólido-líqui- 
do (R) do bagaço de cana e a diluição da enzima (D) são os fatores predominantes que afetam o processo, desta maneira realizou-se um delineamento composto central rotacional (DCCR) para aprofundar na avaliação das variáveis significativas $\mathrm{D}$ e R e buscar uma otimização do processo.

Vale-se ressaltar que as variáveis tempo de hidrólise $(\mathrm{t})$ e concentração de Tween 80 não são significativas para um intervalo de confiança de $95 \%$, porém elas exercem influência sobre a atividade enzimática. Este fato é evidenciado pela maior atividade enzimática obtida no ensaio 4 (nível superior para todas as variáveis), ou seja, estas variáveis afetam o processo positivamente, porém em menor intensidade que as demais variáveis.

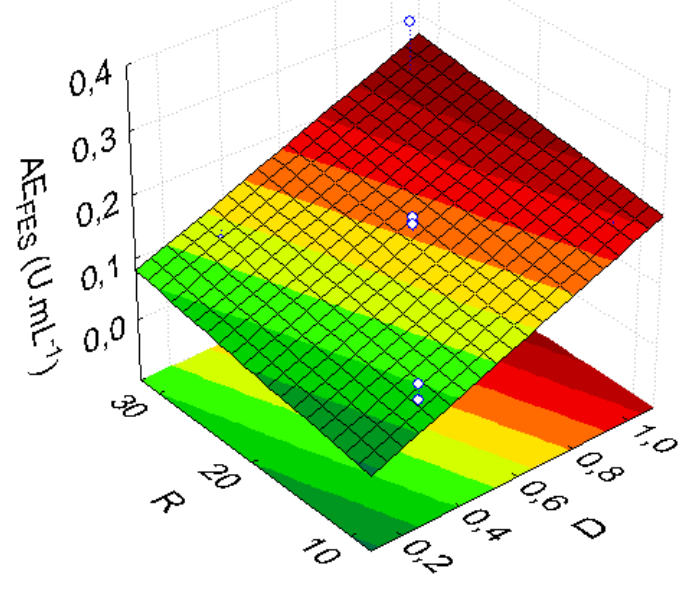

(a)

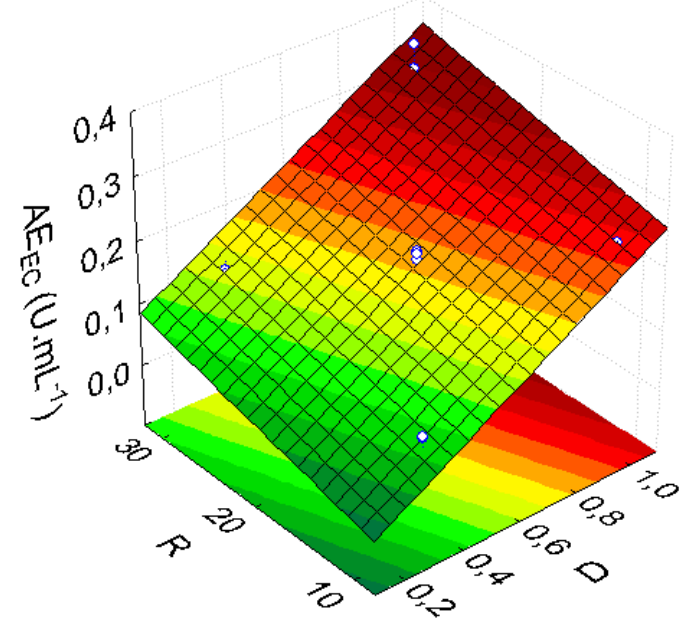

(b)

Figura 1. Superfície de resposta da atividade enzimática obtido no planejamento $2^{4-1}$ da hidrólise do bagaço de cana para: (a) FES; (b) EC.

\section{OTIMIZAÇÃO DAS CONDIÇÓES DA HIDRÓLISE ENZIMÁTICA}

Através do planejamento $2^{4-1}$ nota-se que aumentando a concentração da enzima deverá ocorrer um aumento na $\mathrm{AE}$, entretanto dado o fato de que a solução enzimática produzida por FES foi o próprio extrato bruto, não é possível aumentar sua concentração. A variável razão sólido-líquido do bagaço também possui um limitante, já que não foi possível acrescentar quantidades superiores a 40 g. $\mathrm{L}^{-1}$.

$\mathrm{Na}$ Tabela 5 temos a matriz do planejamento em termos de suas variáveis codificadas e reais, bem como os resultados de atividade enzimática obtidos para cada uma das enzimas estudadas. O delineamento composto central rotacional consistiu de um planejamento $2^{2}$ (ensaios 1 a 4 ), uma quadruplicata no ponto central (ensaios 5 a 8 ) e os pontos axiais (ensaios 9 a 12), responsáveis pela obtenção do modelo quadrático.
Observando-se a Tabela 5, verifica-se que para a enzima produzida por FES obteve-se o melhor resultado no ensaio 4, correspondente aos níveis $(+1)$ para $\mathrm{D}$ e $\mathrm{R}$, com $\mathrm{AE}$ de $0,214 \mathrm{U} \cdot \mathrm{mL}^{-1}$, seguida pelos ensaios 2, 10 e 12 . Para a enzima comercial os ensaios 4 e 10 apresentaram resultados similares de 0,372 U.mL ${ }^{-1}$ e 0,375 U.mL ${ }^{-1}$. De uma maneira geral, as atividades enzimáticas da enzima comercial mostraram-se superiores para todos os ensaios, alcançando um valor médio de 1,84 vezes a atividade da enzima produzida por FES.

Apesar da obtenção de menores atividades enzimáticas na hidrólise utilizando-se a enzima produzida nas FES em relação à enzima comercial ainda podem haver vantagens no uso destas enzimas. A utilização de enzimas produzidas com substratos residuais, como por exemplo o bagaço de cana, além da produçáo por fermentação em estado sólido, a qual necessita de um menor controle operacional, resultam numa matéria-prima de baixo custo. 
Tabela 5. Matriz do planejamento DCCR com quadruplicata no ponto central em seus valores codificados e reais.

\begin{tabular}{|c|c|c|c|c|}
\hline \multirow{2}{*}{ Ensaio } & \multicolumn{2}{|c|}{ Variáveis } & \multicolumn{2}{c|}{ Respostas } \\
\cline { 2 - 5 } & $\mathrm{D}$ & $\mathrm{R}$ & $\begin{array}{c}\mathrm{AE}_{\mathrm{FES}} \\
\left(\mathrm{U}_{\mathrm{mL}}^{-1}\right)\end{array}$ & $\begin{array}{c}\mathrm{AE}_{\mathrm{EC}} \\
\left(\mathrm{U}_{\mathrm{mL}}^{-1}\right)\end{array}$ \\
\hline 1 & $\begin{array}{c}-1 \\
(0,57)\end{array}$ & $\begin{array}{c}-1 \\
(22,9)\end{array}$ & 0,127 & 0,176 \\
\hline 2 & $\begin{array}{c}+1 \\
(0,93)\end{array}$ & $\begin{array}{c}-1 \\
(22,9)\end{array}$ & 0,181 & 0,340 \\
\hline 3 & $\begin{array}{c}-1 \\
(0,57)\end{array}$ & $\begin{array}{c}+1 \\
(37,1)\end{array}$ & 0,146 & 0,235 \\
\hline 4 & $\begin{array}{c}+1 \\
(0,93)\end{array}$ & $\begin{array}{c}+1 \\
(37,1)\end{array}$ & 0,214 & 0,372 \\
\hline 5 & $0(0,75)$ & $0(30)$ & 0,146 & 0,278 \\
\hline 6 & $0(0,75)$ & $0(30)$ & 0,144 & 0,297 \\
\hline 7 & $0(0,75)$ & $0(30)$ & 0,144 & 0,300 \\
\hline 8 & $0(0,75)$ & $0(30)$ & 0,146 & 0,278 \\
\hline 9 & $\begin{array}{c}-1,414 \\
(0,50)\end{array}$ & $0(30)$ & 0,103 & 0,179 \\
\hline 10 & $\begin{array}{c}+1,414 \\
(1,00)\end{array}$ & $0(30)$ & 0,171 & 0,375 \\
\hline 11 & $0(0,75)$ & $\begin{array}{c}-1,414 \\
(20)\end{array}$ & 0,125 & 0,219 \\
\hline 12 & $0(0,75)$ & $\begin{array}{c}+1,414 \\
(40)\end{array}$ & 0,171 & 0,294 \\
\hline
\end{tabular}

A fermentação submersa é amplamente utilizada na produção industrial de celulases. O custo de produção e os baixos níveis destas enzimas são os maiores problemas na produção à nível industrial (Kang et al., 2004). A fermentação em estado sólido é tida como um processo atrativo na produção de celulases, devido a sua viabilidade econômica por necessitar menores investimentos e baixos custos de operação (Yang et al., 2004).

A produção de celulases por FES é reportada por diversos autores utilizando-se diversos substratos residuais, micro-organismos e soluçôes nutrientes (Yang et al., 2004; Latifian et al., 2007).

Segundo Sukumaran et al., (2010) a biomassa lignocelulósica é considerada como a única fonte futura com potencial de produção de combustíveis renováveis, entretanto a comercialização do etanol lignocelulósico é limitado devido a deficiência de tecnologias economicamente viáveis e enzimas de baixo custo.

A estimativa dos efeitos principais para o planejamento DCCR são apresentadas na Tabela 6, com seus respectivos valores de erro padrão, p-valor, valores dos coeficientes das variáveis, na qual os valores destacados em negrito e itálico são significativos para o intervalo de confiança de $95 \%$.

Tabela 6. Estimativa dos efeitos do planejamento DCCR para a hidrólise enzimática do bagaço para as enzimas FES e EC.

\begin{tabular}{|c|c|c|c|c|c|c|}
\hline \multirow{2}{*}{ Intercepto } & \multicolumn{3}{|c|}{ Enzima FES $\left(\mathrm{AE}_{\mathrm{FES}}\right)$} & \multicolumn{3}{c|}{ Enzima Comercial $\left(\mathrm{AE}_{\mathrm{EC}}\right)$} \\
\cline { 2 - 6 } & $\mathrm{p}$-valor & Coeficiente & Erro & p-valor & Coeficiente & Erro \\
\cline { 2 - 6 } & 0,000 & 0,145 & 0,001 & 0,000 & 0,288 & 0,006 \\
\hline $\mathrm{D}(\mathrm{L})$ & 0,000 & 0,027 & 0,001 & 0,000 & 0,073 & 0,004 \\
\hline $\mathrm{D}(\mathrm{Q})$ & 0,028 & 0,003 & 0,001 & 0,696 & $-0,002$ & 0,005 \\
\hline $\mathrm{R}(\mathrm{L})$ & 0,000 & 0,014 & 0,001 & 0,009 & 0,025 & 0,004 \\
\hline $\mathrm{R}(\mathrm{Q})$ & 0,001 & 0,008 & 0,001 & 0,078 & $-0,012$ & 0,005 \\
\hline $\mathrm{D} \times \mathrm{R}$ & 0,023 & 0,003 & 0,001 & 0,334 & $-0,007$ & 0,006 \\
\hline & $\mathrm{R}^{2}=0,857$ & & & $\mathrm{R}^{2}=0,982$ & & \\
\hline
\end{tabular}

A partir da Tabela 6 verifica-se que a estimativa para os efeitos apresentou diferenças entre os resultados obtidos para cada enzima. A hidrólise com a enzima FES indica que todos os parâmetros são significativos, incluindo os termos lineares e quadráticos de $\mathrm{D}$ e $\mathrm{R}$, bem como da interação entre si, para o intervalo de confiança de $95 \%$. Para a enzima comercial os termos lineares $\mathrm{D}$ e $\mathrm{R}$ 
também foram significativos, à exemplo da enzima FES, entretanto os termos quadráticos e a interação entre as variáveis não exerceram influência sobre o processo, assim como pode ser observado pelo p-valor.

Através da análise de variância, pelo teste $\mathrm{F}$, comparando-se o valor do $\mathrm{F}$ calculado com o $\mathrm{F}$ tabelado é possível afirmar se o modelo proposto é válido e se os parâmetros da equação se ajustam aos dados experimentais. A Tabela 7 apresenta os resultados da ANOVA para a hidrólise enzimática com a enzima FES, na qual o valor tabelado de F para um intervalo de confiança de $95 \%$ e com os graus de liberdade é $\mathrm{F}_{\text {regressão }}(5 ; 6 ; 0,05)=4,39$ e para a falta de ajuste temos $\mathrm{F}_{\text {faltadeajuste }}(3 ; 3 ; 0,05)=$ 9,28 (Barros Neto et al., 2010).

Tabela 7. Análise de variância obtida para o planejamento DCCR da hidrólise do bagaço de cana para a enzima FES.

\begin{tabular}{|l|c|c|c|c|}
\hline $\begin{array}{l}\text { Fonte de } \\
\text { variação }\end{array}$ & SQ & GL & MQ & $F_{\text {calc }}$ \\
\hline Regressão & 0,007956 & 5 & 0,001591 & 7,1968 \\
\hline Resíduo & 0,001327 & 6 & 0,000221 & \\
\hline $\begin{array}{l}\text { Falta de } \\
\text { Ajuste }\end{array}$ & 0,001319 & 3 & 0,000440 & 182,344 \\
\hline Erro Puro & 0,000007 & 3 & 0,000002 & \\
\hline Total & 0,009282 & 11 & & \\
\hline $\mathrm{R}^{2}=0,857$ & & & \\
\hline
\end{tabular}

Observando-se a Tabela 7, tem-se um F calculado para a regressáo maior que o $\mathrm{F}$ tabelado, entretanto a razáo $\mathrm{F}_{\text {calc }} / \mathrm{F}_{\text {tab }}$ não é superior a 4. Temos ainda que o $\mathrm{F}_{\text {calc }}$ para a falta de ajuste foi superior ao valor tabelado, de forma que a falta de ajuste é significativa. Ambos os resultados, além do coeficiente de determinação do modelo relativamente baixo $\left(R^{2}=0,857\right)$, indicam que o modelo náo se ajusta adequadamente aos pontos experimentais e que o modelo não é válido.

A superfície de resposta, apresentada na Figura 2, representa graficamente o processo, apesar da não validação do modelo da $\mathrm{AE}$ da celulase em função da razão sólido-líquido $(\mathrm{R})$ e da diluição enzimática (D) para hidrólise do bagaço de cana pré-tratado com a enzima do Trichoderma sp. produzida por FES. Nota-se que para valores maiores $\mathrm{AE}$ da celulase são obtidos em maiores concentraçôes de bagaço e enzimas não diluídas.
À exemplo do planejamento $2^{4-1}$ o valor do coeficiente de correlação foi baixo para a enzima FES devido à utilização da enzima bruta e não homogênea prejudicando a otimização deste processo e a obtenção do modelo. Sendo assim, torna-se necessário avaliar a possibilidade da aplicação de processos de purificação ao extrato enzimático.

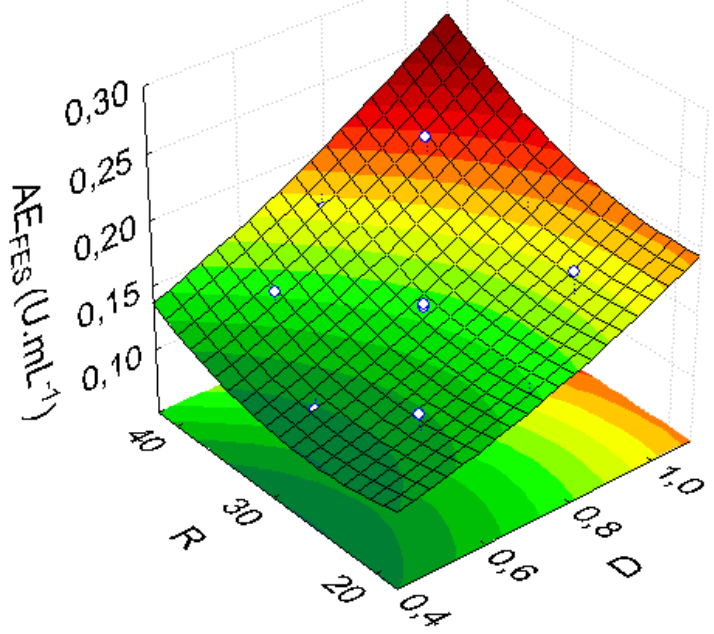

Figura 2. Superfície de resposta da AE da celulase em função de R e D para a hidrólise do bagaço de cana pré-tratado com a enzima FES.

Extratos enzimáticos de $\mathrm{AE}$ mais elevados poderiam ser obtidos por processos de precipitação e concentração das enzimas. No caso da razão sólido-líquido $(\mathrm{R})$, como não é possível obter concentraçóes superiores a 40 g. $\mathrm{L}^{-1}$ devido a saturação do meio, entretanto poderiam ser realizados estudos variando-se dimensão das partículas do bagaço.

De maneira análoga, para a enzima comercial realizou-se a análise de variância e o teste $\mathrm{F}$, apresentado na Tabela 8 , para os mesmos valores de $\mathrm{F}$ tabelado, tem-se $\mathrm{F}_{\text {regressäo }}(5 ; 6 ; 0,05)=4,39$ e $\mathrm{F}_{\text {faltadeauuste }}(3 ; 3 ; 0,05)=9,28$, considerando o mesmo planejamento foi aplicado para ambas enzimas.

Tabela 8. Análise de variância obtida para o planejamento DCCR da hidrólise do bagaço de cana para a enzima comercial.

\begin{tabular}{|l|c|c|c|c|}
\hline $\begin{array}{l}\text { Fonte de } \\
\text { variação }\end{array}$ & SQ & GL & MQ & $F_{\text {calc }}$ \\
\hline Regressão & 0,047958 & 5 & 0,009592 & 64,5655 \\
\hline Resíduo & 0,000891 & 6 & 0,000149 & \\
\hline
\end{tabular}




\begin{tabular}{|l|c|c|c|c|}
\hline $\begin{array}{l}\text { Falta de } \\
\text { Ajuste }\end{array}$ & 0,000481 & 3 & 0,000160 & 1,1708 \\
\hline Erro Puro & 0,000411 & 3 & 0,000137 & \\
\hline Total & 0,048849 & 11 & & \\
\hline $\begin{array}{l}\mathrm{R}^{2}= \\
0,982\end{array}$ & & & & \\
\hline
\end{tabular}

Desta forma, no caso da regressão como $\mathrm{F}_{\text {cal }}$ $>\mathrm{F}_{\text {tab }}$ e sua razão é superior a 4. Ainda, para a falta de ajuste o $\mathrm{F}_{\text {calc }}<\mathrm{F}_{\text {tab }}$, verifica-se que não há falta de ajuste e que o modelo quadrático proposto é válido, sendo possível escrever o modelo matemático empírico de $\mathrm{AE}$ em função das variáveis significativas. Assim a correlação que representa o processo é dada pela Equação (02), com um coeficiente de correlaçáo de $\mathrm{R}^{2}=0,982$.

$$
\begin{aligned}
& A E\left(U \cdot m L^{-1}\right)=0,288+0,085 \times D \\
& +0,014 \times R-0,012 \times R^{2}
\end{aligned}
$$

A superfície de resposta (Figura 3), representa o modelo obtido para a $\mathrm{AE}$ da celulase em função da diluição da enzima (D) e da razão sólido-líquido $(\mathrm{R})$ para a hidrólise enzimática do bagaço de cana pré-tratado pela enzima comercial de $A$. niger.

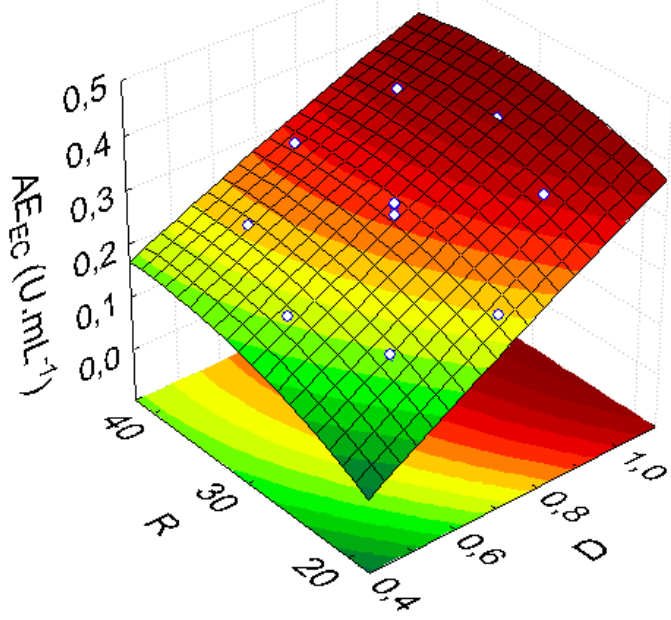

Figura 3. Superfície de resposta da AE da celulase em função de $\mathrm{R}$ e D para a hidrólise do bagaço de cana pré-tratado com a enzima comercial

Observando-se a superfície de resposta apresentada na Figura 3, nota-se que em maiores concentraçóes enzimáticas e em razóes sólido-líquido mais elevados obtêm-se maiores ativida- des enzimáticas. O comportamento para a enzima comercial foi similar ao da enzima produzida por FES, entretanto os valores de AE foram superiores, e verifica-se uma estabilização para os altos valores das variáveis estudadas.

No caso da enzima comercial seria possível aumentar concentração enzimática ou diminuir a diluição (D), já que a mesma é purificada sendo possível obter soluçóes enzimáticas de AE muito superiores, entretanto o foco deste trabalho foi utilizar a enzima comercial como padrão de comparação para a enzima produzida por FES.

Considerando-se que em papel filtro a $\mathrm{AE}$ do extrato bruto enzimático utilizado foi de 0,162 U.mL ${ }^{-1}$, e que a enzima comercial foi diluída para obter a mesma atividade enzimática, verifica-se que sobre o bagaço de cana pré-tratado com $\mathrm{H}_{2} \mathrm{O}_{2}(1 \%)$ ambas enzimas exerciam atividades enzimáticas superiores aos em papel filtro, para todos os planejamentos como mostrado nas Tabelas 3 e 5. Desta maneira, é possível afirmar que o pré-tratamento alcalino oxidativo foi eficaz na disponibilização da celulose ao ataque enzimático sendo um substrato adequado e economicamente viável, desde que os parâmetros de hidrólise sejam convenientemente ajustados.

Bravo et al. (1994) utilizaram tratamento alcalino do bagaço de cana em três razóes sólido-líquido antes da utilização como substrato na produção de proteína microbiana. $\mathrm{O}$ tratamento proporcionou um aumento significativo no crescimento fúngico em comparação com o bagaço não tratado.

Adsul et al. (2004) realizando fermentaçóes submersas em batelada com o fungo Trichoderma viride, testando diversos pré-tratamentos do bagaço de cana na produçáo de celulases e xilanases, obtiveram uma aumento na AE (FPase) de 0,28 U. $\mathrm{mL}^{-1}$ com bagaço sem nenhum tipo de tratamento para 0,62 U. $\mathrm{mL}^{-1}$ usando bagaço pré-tratado com $\mathrm{H}_{2} \mathrm{O}_{2}(10 \%)$, e ainda, realizando um branqueamento com $\mathrm{NaClO}_{2}$ o valor de atividade enzimática encontrado pelos autores foi 0,88 U. $\mathrm{mL}^{-1}$.

Verifica-se que apesar do desempenho superior da enzima comercial, em termos de AE, a enzima produzida por FES apresenta resultados viáveis podendo ser uma alternativa mais econômica nos processos de hidrólise. Outra alternativa na utilização destas enzimas seria o consórcio de enzimas de diferentes fontes, reduzindo o custo e 
aumentando consideravelmente o rendimento do processo de hidrólise enzimática. Conforme Sun \& Cheng (2002) o uso de misturas de celulases de diferentes micro-organismos, ou a utilização de celulases e outras enzimas na hidrólise de materiais celulósicos tem sido amplamente estudada. A adição de $\bigotimes$-glicosidases em sistemas de celulases provenientes de $T$. reesei alcançam maiores teores de sacarificação. As \-glicosidases hidrolisam a celobiose, a qual é um inibidor da atividade enzimática da celulase.

Sabendo-se desta deficiência de algumas enzimas específicas produzidas por certos micro-organismos, a utilização de enzimas de diferentes procedências resulta em um sistema enzimático mais balanceado, náo havendo um fator limitante prejudicial ao processo.

A utilização de resíduos lignocelulósicos de baixo custo, como o bagaço de cana, quando pré-tratados adequadamente podem ser empregados na produção destas enzimas. O pré-tratamento também potencializa a hidrólise enzimática, tornando a celulose acessível ao ataque enzimático. Neste trabalho, foi possível verificar a importância do pré-tratamento tanto na produçáo de celulases, quanto na hidrólise enzimática utilizando-se o tratamento alcalino oxidativo com peróxido de hidrogênio (1\%) no bagaço de cana-de-açúcar.

\section{CONCLUSÓES}

O micro-organismo de origem amazônica Trichoderma sp. foi capaz de produzir celulases na fermentação em estado sólido do bagaço de cana-de-açúcar tratado atingindo níveis de 0,162 U. $\mathrm{mL}^{-1}$. O pré-tratamento alcalino oxidativo com $\mathrm{H}_{2} \mathrm{O}_{2}(1 \%)$ favoreceu a produção das celulases pelo fungo e também disponibilizou os constituintes do complexo lignocelulósico para o ataque enzimático. A partir do planejamento fracionário $2^{4-1}$ foi possível fazer a triagem de variáveis que exerciam influência sobre a hidrólise do bagaço de cana, sendo que a diluiçáo da enzima (D) e razão sólido-líquido do bagaço de cana $(\mathrm{R})$ foram os parâmetros de maior importância tanto para a enzima produzida por FES quanto para a enzima comercial. A partir do delineamento composto central rotacional foi possível obter o modelo que representasse o processo apenas para a enzima comercial. No caso da enzima FES o modelo náo foi validado devido a utilizaçáo do extrato bru- to e heterogêneo, reduzindo significativamente o coeficiente de correlaçáo do mesmo, tornando-se necessários estudos de purificaçáo destas enzimas. Apesar dos teores enzimáticos superiores da enzima comercial, a enzima FES apresentou comportamento similar e a utilização reduziriam os custos do processo de hidrólise devido ao baixo custo da matéria-prima e do processo fermentativo.

\section{AGRADECIMENTOS}

Os autores agradecem à Capes pelo apoio financeiro e ao INPA - Instituto Nacional de Pesquisas da Amazônia pelo fornecimento do micro-organismo.

\section{REFERÊNCIAS BIBLIOGRÁFICAS}

Adsul, M.G., Ghule, J.E., Singh, R., Shaikh, H., Bastawdea, K.B., Gokhale, D.V., Varma, A.J. Polysaccharides from bagasse: applications in cellulase and xylanase production. Carbohydrate Polymers, v.57, p.67-72, 2004.

Bansal, P., Hall, M., Realff, M. J., Lee, J. H., Bommarius, A. S. Modeling cellulase kinetics on lignocellulosic substrates. Biotechnology Advances, v.27, p.833-848, 2009.

Barros Neto B., Bruns, R. E., Scarminio, I. S. Como fazer experimentos - Aplicaçôes na ciência e na indústria. 4.ed. Editora Bookman, 2010.

Bravo, O., Ferrer, A., Aiello, C., Ledesma, A., Davila, M. Growth of Chaetomium-Cellulolyticum in Solid-State Fermentation of Sugar-Cane Bagasse Treated with Water and Alkali at Several Liquid/Solid Ratios. Biotechnology Letters, v.16, n.8, p.865-870, 1994.

Chandra, M., Kalra, A., Sharma, P.K., Kumar, H., Sangwan, R.S. Optimization of cellulases production by Trichoderma citrinoviride on marc of Artemisia annua and its application for bioconversion process. Biomass and bioenergy, v.34, p.805-811, 2010.

Chundawat, S. P. S., Beckham, G. T., Himmel, M. E., Dale, B. E. Deconstruction of Lignocellulosic Biomass to Fuels and Chemicals. Annu. Rev. Chem. Biomol. Eng., v.2, p.121-45, 2011. 
Eriksson, T., Börjesson, J., Tjerneld, F. Mechanism of surfactant effect in enzymatic hydrolysis of lignocellulose. Enzyme and Microbial Technology, v.31, p.353-364, 2002.

Fitzpatrick, M., Champagne, P., Cunningham, M. F., Whitney, R. A. A biorefinery processing perspective: Treatment of lignocellulosic materials for the production of value-added products. Bioresource Technology, v.101, p.8915-8922, 2010.

Ghose, T. K. Measurement of cellulase activities. Pure and Applied Chemistry, v.59, p.257-268, 1987.

Imai, M., Ikari, K., Suzuki, I. High-performance hydrolysis of cellulose using mixed cellulase species and ultrasonication pretreatment. Biochemical Engineering Journal, v.17, p.79-83, 2004.

Kang, S. W., Park, Y. S., Lee, J. S., Hong, S. I., Kim, S. W. Production of cellulases and hemicellulases by Aspergillus niger KK2 from lignocellulosic biomass. Bioresource Technology, v.91, p.153-156, 2004.

Krishna S. H., Rao, K. C. S., Babu, J. S., Reddy, D. S. Studies on the production and application of cellulose from Trichoderma reesei QM-9414. Bioprocess Engineering, v.22, p.467-470, 2000.

Latifian M., Hamidi-Esfahani, Z., Barzegar M. Evaluation of culture conditions for cellulase production by two Trichoderma reesei mutants under solid-state fermentation conditions. Bioresource Technology, v.98, p.3634-3637, 2007.

Mandels, M., Weber, J. The production of cellulases. Advances in Chemistry Series, v.95, p.391414, 1969.

Miller, G. L. Use of dinitrosalicylic acid reagent for determination of reducing sugar. Analytical Chemistry. v.31, n.3, p.426-428, 1959. 38.

Palonen, H., Tjerneld, F., Zacchi, G., Tenkanen, M. Adsorption of Trichoderma reesei CBH I and EG II and their catalytic domains on steam pretreated softwood and isolated lignin. Journal of Biotechnology, v.107, p.65-72, 2004.
Pandey, A., Soccol, C. R., Mitchell, D. Biotechnological potential of agro-industrial residues. I: sugarcane bagasse, Bioresource Technology, v.74, p.69-80, 2000a.

Pandey, A., Soccol, C. R., Mitchell, D. New developments in solid state fermentation: I-bioprocesses and products. Process Biochemistry, v.35, p.1153-1169, 2000b.

Park, Y.S., Kang, S.W., Lee, J.S., Hong, S.I., Kim S.W. Xylanase production in solid state fermentation by Aspergillus niger mutant using statistical experimental designs. Appl Microbiol Biotechnol, v.58, p.761-766, 2002.

Scheufele, F.B. Bioconversão de resíduos agroindustriais por micro-organismos do bioma amazônico produtores de enzimas lignoceluloliticas. Toledo, PR: Universidade Estadual do Oeste do Paraná, 2012, 119 p. Dissertação (Mestrado).

Singhania, R. R., Sukumaran, R. K., Patel, A. K., Larroche, C., Pandey, A. Advancement and comparative profiles in the production technologies using solid-state and submerged fermentation for microbial cellulases. Enzyme and Microbial Technology, v.46, p.541-549, 2010.

Sukumaran, R. K., Surender, V.J., Sindhu, R., Binod, P., Janu, K.U., Sajna, K.V., Rajasree, K.P., Pandey, A. Lignocellulosic ethanol in India: Prospects, challenges and feedstock availability. Bioresource Technology v.101, p.4826-4833, 2010.

Sun, Y., Cheng, J. Hydrolysis of lignocellulosic materials for ethanol production: a review, Bioresource Technology, v.83, p.1-11, 2002.

Yang, Y.H.; Wang, B.C.; Wang, Q.H.; Xiang, L.J.; Duan, C.R. Research on solid-state fermentation on rice chaff with a microbial consortium. Colloids and Surfaces B: Biointerfaces, V.34, p.1-6, 2004.

Zhang, Y. H. P., Himmel, M. E., Mielenz, J.R. Outlook for cellulase improvement: Screening and selection strategies. Biotechnology Advances, v.24, p.452-481, 2006.

Artigo submetido em 21/04/2012, aceito em 09/07/2012 